\title{
The constraints on minority housing choices, New York City 1978-1987.
}

\author{
by Emily Rosenbaum
}

\begin{abstract}
This study uses a multivariate analysis to evaluate the housing and neighborhood characteristics that predict the residential choices made by non-Hispanic white, non-Hispanic black, Puerto Rican, and other Hispanic mover households in New York City from 1978 to 1987. This study evaluates minority housing choices in a multigroup context, rather than in a two-group context that implicitly assumes that minority groups compete for housing with only whites. After the influence of household characteristics is controlled, the results show that indicators of low-quality housing and poor neighborhood conditions significantly increase the likelihood that the household that moves in is a minority one, most likely Puerto Rican. Moreover, location in an area dominated by a particular minority group significantly increases the chance that the housing unit is occupied by a household belonging to that same group. By constraining minority housing choices, housing market segmentation effectively predetermines the types of housing units and neighborhoods that are available to different groups, and thus maintains racially and ethnically separate neighborhoods.
\end{abstract}

\section{@ COPYRIGHTUniversity of North Carolina Press 1994}

Extreme levels of racial segregation have long characterized many American cities, despite two important developments: the growth of a black middle class with the income to facilitate residential mobility and increasing support by whites for racial integration (Massey \& Denton 1993). Ecological analyses have shown that the separation of whites and blacks has been maintained by the near-inevitability of complete racial turnover following black entry into formerly white neighborhoods (Duncan \& Duncan 1957; Massey \& Mullan 1984; Taeuber \& Taeuber 1965), even though initial black in-movers are of a status at least equal to that of resident whites (Long \& Spain 1978). The enduring white reluctance to live near blacks has created a segmented housing market, in which the collective actions of neighborhood residents and institutional agents (such as real estate agents) operate to constrain black residential choices to areas that are more ethnically diverse, less prosperous, and of lower quality than those to which whites move. For instance, housing market audit studies conducted over the past two decades have documented the existence of racial steering and discriminatory treatment of minority home-seekers by real estate agents (Newburger 1984; Pearce 1979; Turner \& Wienk 1993; Wienk et al. 1979; Yinger 1991). Discrimination has been linked empirically to continued racial segregation (Galster 1986) and may also explain the variety of racial housing inequalities that remain after controlling for socioeconomic status. Among such inequalities are blacks' relative inability (when compared to whites, Asians, and Hispanics) to convert income and status gains into improved housing and neighborhoods (Massey \& Denton 1985; Massey \& Fong 1990; Massey \& Gross 1991; Villemez 1980), the increased likelihood of black, versus white, turnover in rundown housing units located in deteriorated central city neighborhoods (Marullo 1982, 1985), and racial disparities in ownership and housing quality (Alba \& Logan 1993; Bianchi, Farley \& Spain 1982; Jackman \& Jackman 1980; Wilson 1979). Thus, evidence indicates that market constraints not only sustain racial separation at the aggregate level, but may also serve to reduce blacks' housing consumption relative to that of other groups.

With the exception of Puerto Ricans, Hispanic segregation from whites is moderate and largely explained by differences in socioeconomic status and nativity (Bean \& Tienda 1987; Denton \& Massey 1988; Massey \& Denton 1987). While white/Hispanic segregation during the 1960s appeared to be largely due to ethnic preferences for seclusion, increasing isolation during the 1970s, a decade of rapid immigration and economic stagnation, indicates the rising importance of involuntary factors (Bean \& Tienda 1987). Such a conclusion is buttressed by evidence of discriminatory treatment of home-seeking Hispanics by real estate agents (Garza 1983; James \& Tynan 1986; Turner \& Wienk 1993; Yinger 1991). Furthermore, the finding that Hispanics are less likely than statistically comparable Anglos to own their own homes (Alba \& Logan 1993; Krivo 1986) suggests that market segmentation may adversely affect Hispanics' housing consumption as well as that of blacks.

Compared to other Hispanic groups, Puerto Ricans exhibit a unique residential pattern: isolation from whites and proximity to blacks (Bean \& Tienda 1987; Massey \& Bitterman 1985; Rosenberg \& Lake 1976). This pattern is attributed to very low socioeconomic status (which hinders relocation to higher status white neighborhoods) and black racial ancestry (which draws Puerto Ricans toward residence near or within black neighborhoods); since whites avoid black areas, Puerto Ricans become passive or "bystander" victims of white prejudice (Massey \& Bitterman 1985). Moreover, the finding that black race increases the chance that Hispanics encounter inadequate treatment by real estate agents (Yinger 1991) 


\section{The constraints on minority housing choices, New York City 1978-1987.}

underscores the problems Puerto Ricans may encounter when seeking new housing. Indeed, among all Hispanic subgroups, Puerto Ricans are least likely to own their homes (Alba \& Logan 1993; Krivo 1986).

In this study I examine the constraints on minority housing options within a multiethnic context. While overwhelming evidence points to continuing discrimination in the housing market as the crucial factor maintaining segregation at the aggregate level, this analysis uses individual-level data to focus on the types of housing units chosen by recently moved households who differ in race/ethnicity. Specifically, by identifying the predictors of in-movement by non-Hispanic white, non-Hispanic black, Puerto Rican, and other Hispanic(1) households in New York City, I show that constraints in the urban housing market effectively predetermine the types of housing opportunities available to blacks and Hispanics, and thus serve to isolate whites from minorities and to contribute to racial/ethnic disparities in housing consumption. Because the chances of white, black, Puerto Rican, and other Hispanic in-movement are estimated simultaneously, this approach marks a fundamental departure from earlier studies that implicitly assume that a particular minority group competes with only whites for housing within a "closed" or two-group system (Rosenberg \& Lake 1976). While studies of neighborhood transition increasingly recognize that interminority competition may alter the path of neighborhood succession (Denton \& Massey 1991; Lee \& Wood 1991; Rosenberg \& Lake 1976), no study to date has incorporated this perspective into an investigation of housing consumption differences using individual-level data. The basic issues addressed in this study are whether the market and social forces that have been shown to restrict black access to white-vacated and high-quality housing elsewhere also exist in New York, and whether these forces also constrain the housing choices of Puerto Ricans and other Hispanics. While the focus on New York clearly limits generalizing the results to other cities, the large and diverse minority population in New York makes it an ideal location for studying interminority competition and interaction in the urban housing market. (Blacks constituted $25 \%$ and Hispanics $24 \%$ of the population in 1990.) Equally important, the consistently high level of minority segregation from whites suggests the presence of strong social and market barriers against intergroup residential mixing. White-black dissimilarity stood at .824 in 1980 and .853 in 1990, while the corresponding indices for white-Hispanic dissimilarity were .638 and .655 respectively.(2)

\section{Household Mobility, Housing Searches, and Constraints on Choice}

The theoretical framework that guides the analysis builds on residential mobility models and highlights how market and social forces may limit home-seekers' awareness of available housing and how such constraints may differentially affect the choices of minority households.

The analysis focuses on the choices made by households who have recently moved. The decision to move is typically viewed as a response to mismatched household needs/preferences and housing-unit characteristics (Quigley \& Weinberg 1977). Upon realizing this mismatch, the household begins a search for a new unit, with the goal of locating and evaluating acceptable alternatives to its current unit (Lake 1981). Ultimately, the household selects the unit which best suits its needs and budget. For present purposes, the factors that influence housing choice rather than the decision to move are most relevant.

The pool of available units from which the household chooses is shaped by two broad factors: household characteristics and knowledge of available vacancies. Household characteristics determine needs and preferences, and thus influence the type of unit the household will consider. Among such characteristics are socioeconomic status (since the household cannot realistically consider a unit it cannot afford) and life-cycle factors, which influence need for space and location.

Knowledge of available vacancies depends on a number of factors, including the residential locations of friends and family, and information acquired through advertisements or formal contacts, such as real estate agents. Race/ethnicity can also influence a household's knowledge of available vacancies. For instance, the extent to which members of different groups interact informally in social or work environments may influence the readiness with which they share information on available housing in their neighborhoods. In addition, landlords and area residents may employ a variety of "selective recruitment" tactics (Buell 1982) to target preferred tenants/neighbors, such as advertising in a foreign language, in a particular newspaper, or by word of mouth (DeSena 1990; Lake 1981; Rieder 1985; Susser 1982). The actions of institutional agents, such as real estate brokers, may be particularly important in determining the amount and content of housing market information that is provided to different types of households. Housing-market audits have documented that black and Hispanic home-seekers are told about and shown fewer vacancies and receive less information about financing than comparable white home-seekers (Turner \& Wienk 1993; Wienk et al. 1979; Yinger 1991). One consequence of these various social and market constraints may be that the ideal unit may not be among the choices 


\section{The constraints on minority housing choices, New York City 1978-1987.}

known to the household, who must then decide to postpone the move or settle for a less-than-perfect match to its needs and preferences. Moreover, differences in the quantity and quality of information available to different racial/ethnic groups will result in destinations that differ by race and ethnicity (Lake 1981; Turner \& Wienk 1993).

The link between household and housing characteristics can be examined from the perspective of the housing unit (Marullo 1982). That is, to say that different households prefer different units is equivalent to saying that a specific type of unit attracts a specific type of household. The goal of the present study is to identify the unit characteristics that increase the chance that a black, Puerto Rican, or other Hispanic household moves in, relative to the chance that a white household moves in. One unit characteristic of interest is housing quality. Because the desire for high-quality housing and neighborhoods does not differ across race/ethnicity (Darden 1987), quality should not, all other things being equal, determine who moves into a particular unit. However, other things are often not equal; after controlling for income and household composition, if low housing and neighborhood quality significantly increase the likelihood that a black, Puerto Rican, or other Hispanic household moves in, rather than a white household, then a portion of this result can be attributed to external constraints on minority housing options, and a system of "limited access" can be said to prevail. Another characteristic of interest is the race/ethnicity of the prior household, or the extent to which minority access to housing vacated by other groups (and particularly by whites) is limited. If market and social barriers prevent residential mixing, then, after controlling for income and preferences, exchange between groups will be less likely than exchange within groups. Finally, the racial/ethnic composition of the surrounding area is also of interest; if market and social constraints maintain the spatial separation of racial/ethnic groups, then areal racial/ethnic composition should significantly predict the racial/ethnic identity of in-moving households. In this framework, the decision to move is given; the analysis is restricted to housing units in which a move has already occurred.

A basic hypothesis concerning the types of units that increase the likelihood of minority versus white occupancy emerges from the preceding discussion. Consistent with evidence of persistent housing discrimination, after household characteristics are controlled for, black and Hispanic in-movement will be more likely than white in-movement in units vacated by other minorities and in those located outside of predominantly white areas. In addition, the chance of minority in-movement should be heightened in undermaintained units and those located in areas that are unfavorably evaluated and that contain boarded-up buildings.

\section{Data and Methods}

\section{DATA SET}

The data are from the triennial New York City Housing and Vacancy Survey (HVS), a multistage probability sample of over 18,000 housing units located throughout the five boroughs (Manhattan, Queens, Brooklyn, Staten Island, and the Bronx). Sampling weights adjust for the design effects of stratification and clustering. The HVS is conducted by the Census Bureau under contract to New York City in compliance with city and state laws regarding rent regulation (U.S. Bureau of the Census 1979, 1982, 1985, 1988). The specific data set created for the analysis consists of occupied housing units matched between successive pairs of the 1978, 1981, 1984, and 1987 waves of the HVS, and the analysis concentrates on moves during three time periods (1978-81, 1981-84, 1984-87).

The HVS is similar to the American Housing Survey (AHS) in that the housing unit is the unit of observation, rather than the household. The measures of housing and neighborhood quality in the HVS are, however, neither as numerous nor as detailed as those available within the AHS, and are assessed only for rental units (70\% of all units citywide). Although this limitation restricts the present analysis to units in the rental market, the many other attributes of the HVS make it a desirable data set with which to work. In addition to its longitudinal format, the HVS differentiates between rent-regulated units and units whose rents are not subject to regulation, and identifies units in public housing, which provides insight into how participation in different sectors affects housing consumption and interaction patterns. Most important is the large sample size of the HVS, which in combination with the exclusive focus on a highly diverse city, provides a larger number of minority (and particularly Puerto Rican) mover households than that available in the AHS.

As stated above, the analysis focuses on movers, or more precisely, on housing units that experienced a change in occupancy between two successive survey dates. A change in occupancy is identified when the householder at time 2 reports having moved since, and including, the prior survey year. For example, units in which a move occurred between 1984 and 1987 are those in which the householder in 1987 reports having moved in at any time during 1984, 1985, 1986, 


\section{The constraints on minority housing choices, New York City 1978-1987.}

or 1987. Although this strategy may overestimate the occurrence of change (by misclassifying some households at time 2 as in-movers), the amount of error is small since the survey is done in February and March of the survey year. Thus, the risk period for misclassification is at most three months, and that for correct classification is at least nine months, of the prior survey year. However, to eliminate this error as fully as possible, housing units in which the householder reported the prior survey year (e.g., 1984) as the move-in date at time 1 (1984) as well as at time 2 (1987) are assigned mover status for the former but not the latter year. This procedure, which is based on the assumption that a housing unit will not undergo a change in occupancy more than once in a single calendar year, eliminated $6.9 \%$ of cases from the analysis.

Race/ethnicity of the household is defined as that of the householder, and four mutually exclusive categories of race and Hispanic origin are used: non-Hispanic white, non-Hispanic black, Puerto Rican, and other Hispanic. The race item was changed in 1987 from an interviewer observation to a direct question, resulting in a slight underrepresentation (through nonresponse) of both white and black households. Insofar as nonresponse is random, this change should have little impact on the analysis. Hispanics are identified from two items -- Hispanic national origin, and birthplace and parentage -which were also changed in 1987. In the three early surveys, the Hispanic national origin item offered eight response categories (Mexican, Mexicano, Mexican-American, Chicano, Puerto Rican, Cuban, Central or South American, and other Spanish), but in 1987 the corresponding item offered only a simple yes/no response option. To identify Hispanic subgroups in 1987, the birthplace and parentage response categories were expanded beyond the three offered previously (U.S., Puerto Rico, and other) to better reflect the diversity of the city's immigrant population.

The New York City Hispanic population differs from the national Hispanic population. Puerto Ricans make up about half of all Hispanics in New York, and Dominicans constitute the largest single group of non-Puerto Rican Hispanics (Gurak \& Kritz 1985; Mann \& Salvo 1984). The majority of non-Puerto Rican Hispanics in New York, however, is composed of a broad array of groups originating mainly from Central and South America. Although Mexicans and Cubans are large groups at the national level, they make up a relatively small share of New York's Hispanic population (Mann \& Salvo 1984). Because the Hispanic-origin categories offered in the period from 1978 to 1984 reflected the national profile, while the 1987 birthplace-and-parentage items mirrored the city mix, the item changes resulted in more other Hispanic households in 1987 than would have been the case if no changes had occurred. Evidence suggests that of all other Hispanic subgroups, Dominicans are most underrepresented in the HVS. Consequently, the attributes of other Hispanic households are largely influenced by the characteristics of other non-Puerto Rican subgroups, including relatively higher socioeconomic status and a lower prevalence of mixed and black race (Gurak \& Kritz 1985); this may enhance the likelihood of white/other Hispanic housing exchange. Finally, since Puerto Rican birthplace and parentage remained consistent over all survey years, the representation of Puerto Rican households was unaffected by item changes.

The housing and neighborhood characteristics available in the HVS and used in the analysis are described in detail in Table 1, along with the household characteristics that are used as controls for preferences (householder age and household composition) and economic status (household income and receipt of public assistance). All are dichotomies (coded 1 if the category applies, 0 otherwise) except householder age and household income. Since housing characteristics influence who moves in, neighborhood and housing characteristics are measured at time 1 , with the exception of rent regulation status.(3)

About $38 \%$ of New York City's housing stock is composed of rental units subject to rent regulation, of which $14 \%$ is rent-controlled (U.S. Department of Housing and Urban Development 1991). Empirical research on the impact of regulation on the housing market is inconclusive, yet regulation has been shown to depress mobility rates, presumably because of the financial benefits that accrue to long-term residents of regulated units (U.S. Department of Housing and Urban Development 1991). For the purposes of the present study, this impact of regulation is less important (since the focus is on units in which a move occurred) than the influence regulation may have on housing searches, especially in regard to advertised vacancies and the use of intermediaries. Because of great demand and limited supply, most vacancies in controlled units during the 1960s were not advertised, and they were generally filled by friends or relatives of the current tenants, neighbors, or owner (Denowitz 1980), or by persons learning of the vacancy through such informal means as asking the doorman or superintendent. Anecdotal evidence suggests that these informal channels continue to operate, and thus may limit household knowledge of available vacancies to its most personal and immediate contacts. Moreover, those units that are advertised are largely handled by real estate brokers, whose behavior can greatly influence the amount and content of information available to individual home-seekers. Thus, in the regulated and unregulated markets alike there is the potential for external constraints on minority housing choices. 


\section{The constraints on minority housing choices, New York City 1978-1987.}

In 1987 sampled units were coded for location in one of 54 "subborough areas" or "subareas," geographic units composed of entire census tracts and exceeding 100,000 population. Four categories of subarea racial and ethnic composition were created to reflect group dominance. In predominantly white subareas, at least $75 \%$ of households are white or other race; in mixed Hispanic and mixed black subareas, $25 \%$ to $74 \%$ of households are white or other, and Hispanics outnumber blacks (in the former) and blacks outnumber Hispanics (in the latter); finally, in predominantly nonwhite subareas, less than $25 \%$ of households are white or other. In the analysis subarea racial/ethnic composition is measured at time 1.(4) Since some units surveyed in 1978, 1981, or 1984 were lost to the survey by 1987, missing subarea data are inevitable ( $9 \%$ of the analytical sample). To retain these cases in the analysis, a dummy missing-data variable (coded 1 if missing, 0 otherwise) is included, and missing cases in the substantive subarea composition dichotomies are set to $0 .(5)$

Household (pretax, posttransfer) income is reported for the prior calendar year as a single dollar value that represents the sum of contributions (by the householder, his/her spouse, and all other members combined) from three TABULAR DATA OMITTED sources: salary and wages, own business or profession, and other sources. Unlike other surveys, the HVS does not provide imputed values for missing income reports, and the 1978-87 surveys did not collect the necessary information (such as education and occupational status) that would allow the user to impute values that vary across households. Missing data vary slightly by race and Hispanic origin, with some $16 \%$ of white and other Hispanic, and $15 \%$ of black and Puerto Rican households in the analytical sample not reporting income. To avoid losing these cases, a missing-data dummy variable is included, and missing observations of income are set to 0.(6)

Because the data set includes three separate time periods, it is possible for a given housing unit to appear more than once in the analysis. For example, if a housing unit experienced a change in occupancy between 1978 and 1981, and then again between 1984 and 1987, it would appear twice in the analysis. Of the unique housing units in the sample, 26\% appear more than once, which means that $44 \%$ of the observations reflect "repeaters." To control for correlated errors between cases included multiple times, a set of five dummy variables is used to indicate whether a given case is in the sample more than once and in a particular borough. This procedure assumes that common errors are due to characteristics associated with borough location. The effects of these dummies, though, are not statistically significant and, like the results of the missing-data dummies, are not featured in the discussion of the results.

\section{ANALYTICAL TECHNIQUES}

Multinomial logistic regression is used to assess the independent effects of each predictor on the likelihood of in-movement by a household belonging to a particular racial/ethnic group. Logit models express the natural logarithm of the odds ratio, the logit, as a linear function of the explanatory variables (Hanushek \& Jackson 1977). With a k-category dependent variable, there are $\mathrm{l}(\mathrm{k}-1)^{\wedge} / 2$ distinct odds, $\mathrm{k}-1$ of which are independent (Alba 1987). Among its desirable properties as a measure of association, the odds ratio depends only on the strength and direction of association between variables and is unaffected by sample size or variations in the marginals (Fienberg 1989; Knoke \& Burke 1980).

For the universe of rental units that experience a change in occupancy between two survey dates, the following multinomial logit model is estimated:

$\ln \left(! P\right.$. sub.i $\mathrm{i}^{\wedge} / ! P$. sub.j $\left.\mathrm{j}^{\wedge}\right)=!$ B.sub. $\mathrm{i}^{\wedge} \mathrm{X}$

where $X$ is the vector of geographical, unit and neighborhood quality, and household characteristics for a given housing unit, !P.sub.i^ the odds that the in-moving household belongs to racial/ethnic group $\mathrm{i}$, and !P.sub.j^ the odds that the in-moving household belongs to group j; the outcome $\mathrm{j}$ is used as a baseline for comparison (Aldrich \& Nelson 1984). Since the outcome of interest is minority occupancy, the baseline or contrast outcome (corresponding to the denominator probability in the odds ratio) is always white occupancy. Sampling weights are scaled down to remove the design effects described above while maintaining unweighted sample frequencies. Maximum likelihood techniques available within the SAS Procedure CATMOD (SAS Institute 1985) are used.

Results

CHARACTERISTICS OF HOUSEHOLDS 


\section{The constraints on minority housing choices, New York City 1978-1987.}

Before proceeding to the multivariate analysis, it will be useful to explore the characteristics of the households under study, since many factors can influence the types of housing and neighborhoods a household prefers and can afford, and thus can contribute to differing patterns of consumption. To accomplish this task, Table 2 presents descriptive statistics of the variables used in the multinomial logit model.

According to all available indicators of economic well-being, black and Hispanic mover households are clearly less well off than comparable white households. The economic disadvantage of Puerto Ricans, however, is striking, in terms of both average income and reliance on public assistance.

Racial/ethnic differences in economic status are related to differences in household composition (Bianchi 1981). In particular, compared to white households, black and Hispanic households are far more likely to consist of a single parent and dependent children. Single-parent headship is particularly pronounced for black and Puerto Rican households, increasing the risk of poverty for these two groups (Garfinkel \& McLanahan 1986).

The spatial distributions of the four groups vary (rows 8-12 and 13-16). Blacks and Puerto Ricans show the highest degree of concentration in a single borough: blacks in Brooklyn and Puerto Ricans in the Bronx. Whites are most likely to move to units in predominantly white subareas and least likely to move to units in ethnically diverse subareas. Consistent with aggregate spatial patterns, other Hispanic households are more likely than black and Puerto Rican households to move into predominantly white subareas, while subareas with a nonwhite majority are more frequently the destinations of black and Puerto Rican households. While these spatial patterns may be influenced by varying preferences for certain neighborhoods (Farley 1993), they may also arise from market divisions along racial/ethnic lines, an interpretation that is also supported by the propensity for in-movers to replace households of identical race/ethnicity (rows 17-20).

In general, racial/ethnic differences in housing and neighborhood quality mirror differences in economic status. Hispanic and black renter households are less likely than white renter households to move into units located in neighborhoods that received good or excellent evaluations from the previous occupants, and more likely to acquire undermaintained units and those in neighborhoods with boarded-up buildings. Moreover, the finding that more black than other Hispanic households move into lower-quality housing, despite roughly similar incomes, may indicate that discrimination triggered by black race prevents the acquisition of desired housing. Finally, of all groups, blacks and Puerto Ricans are most likely to move into public housing units.

In sum, disparities in household well-being indicate that the average black and Hispanic household is unlikely to be able to afford the same types of housing and neighborhoods as the average white household. Given these differences, variations in spatial patterns and housing consumption come as little surprise. However, once differences in household characteristics are held constant, if low housing and neighborhood quality significantly increase the odds that a minority (relative to a white) household moves in, then a system of limited minority access to quality housing can be said to prevail. Naturally, since only the outcomes of housing market transactions are observed, I cannot quantify the extent to which external constraints contribute to observed differences but can only infer that they exist.

TABLE 2: Summary Household, Neighborhood, and Housing Characteristics of New York City Renter Households who Recently Moved, According to Race/Ethnicity of

Householder(a)

All

Economic status

Receives public assistance

17.5 Median household income (b)

16,414

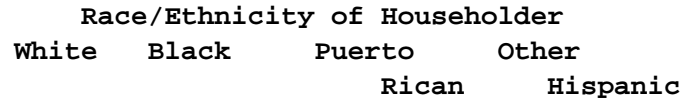

$\begin{array}{llll}3.6 & 23.4 & 44.8 & 17.6\end{array}$

$23,034 \quad 13,098 \quad 9,431 \quad 13,678$

$\begin{array}{llll}37.7 & 36.1 & 36.2 & 36.0\end{array}$ 


\section{The constraints on minority housing choices, New York City 1978-1987.}

36.9

\begin{tabular}{|c|c|c|c|c|}
\hline Husband and wife alone & 20.7 & 10.4 & \multicolumn{2}{|c|}{12.8} \\
\hline 15.2 Husband and wife with children & $\begin{array}{lll}n & 18.3 & 1\end{array}$ & 18.2 & 20.8 & 33.7 \\
\hline 20.5 Single parent & 5.5 & 28.4 & 35.6 & 17.9 \\
\hline 17.9 One person & 40.0 & 28.7 & 21.4 & \\
\hline 31.4 Other (c) & 15.5 & 15.4 & 11 & \\
\hline
\end{tabular}

17.1

15.0

Borough

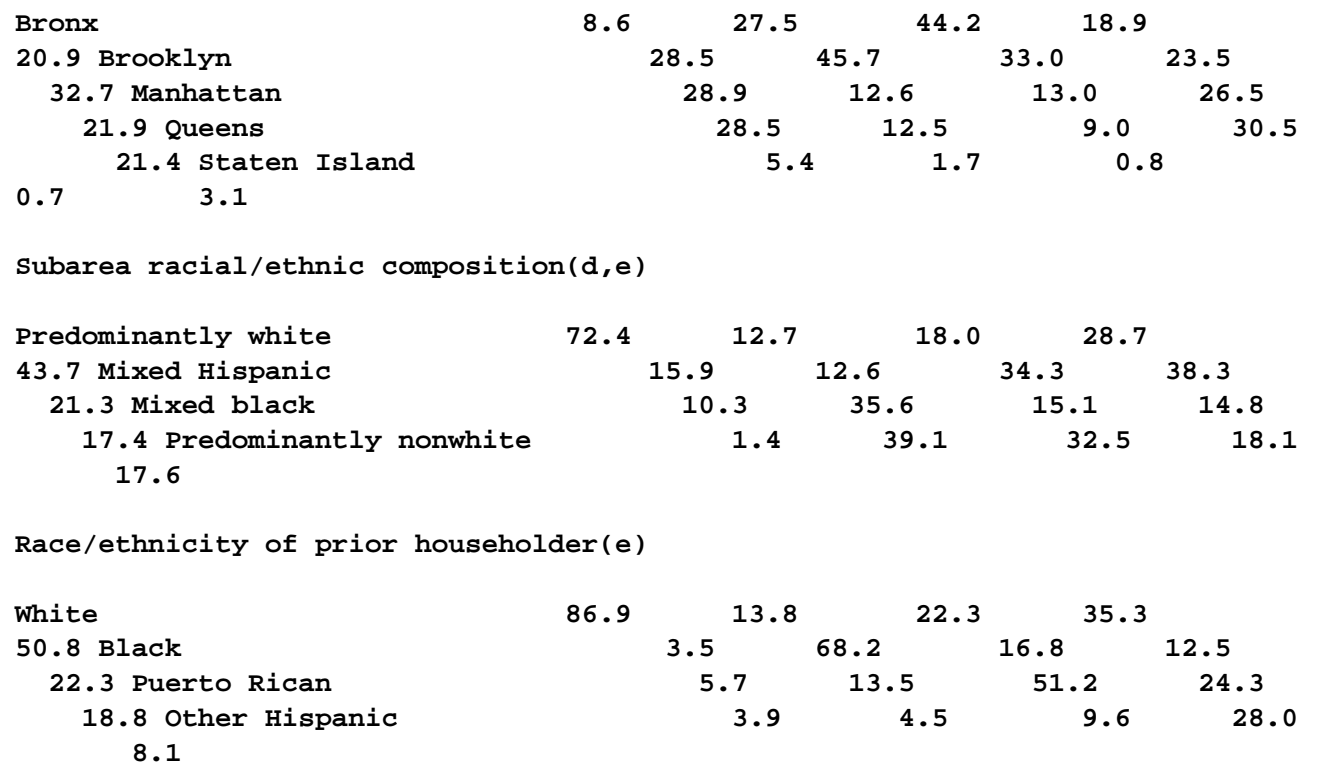

Neighborhood quality $(e, f)$

Evaluation

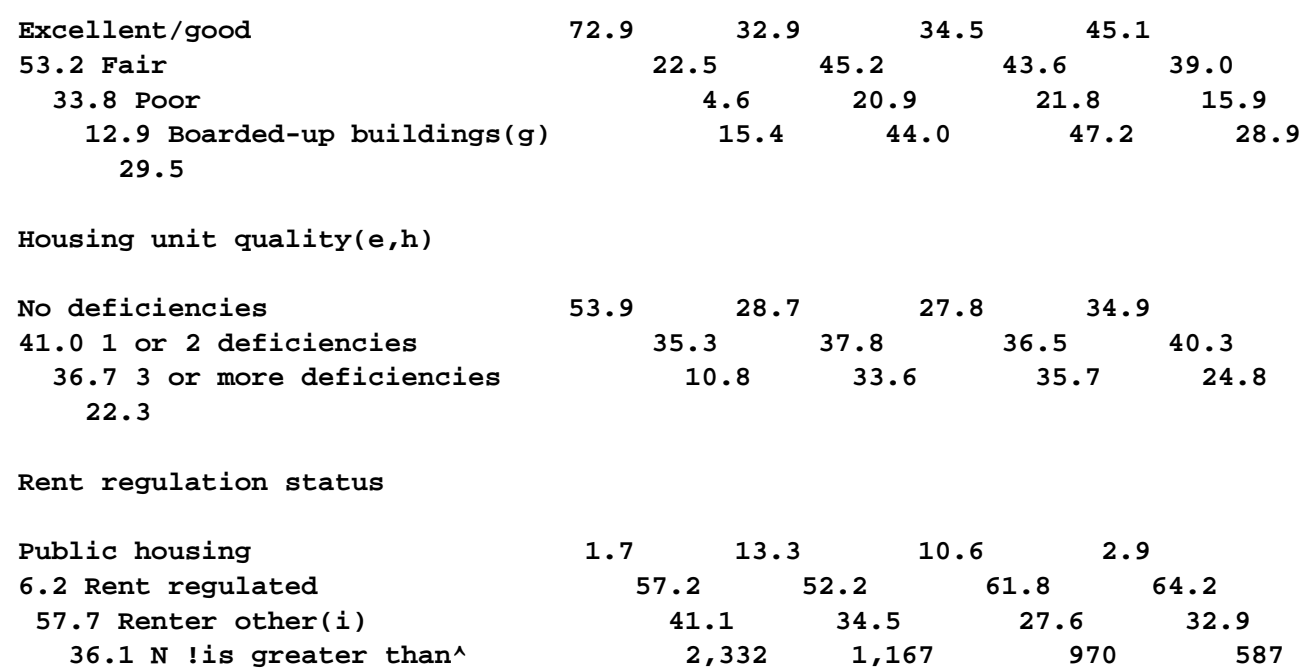




\section{The constraints on minority housing choices, New York City 1978-1987.}

5,056

a Figures are percentages, except where noted. Figures may not add up to $100 \%$ due to rounding. All variables are measured at time 2 except where noted.

b In 1986 dollars

c Represents other family and nonfamily households without children.

d In predominantly white subareas, at least $75 \%$ of households are white or other race; in mixed Hispanic subareas $25 \%$ to $74 \%$ of households are white or other race and Hispanics outnumber blacks, while in mixed black subareas blacks outnumber Hispanics; in predominantly nonwhite subareas, less than 25\% of households are white or other race.

e Measured at time 1 .

f Previous occupant's evaluation of neighborhood as "place to live."

g Previous occupant's report of boarded-up buildings in the neighborhood.

h Maintenance deficiencies reported for previous 90 days include rodent infestation, cracks and/or holes in walls/floors, insufficient heat, heating system breakdown, missing plaster. Reported by previous occupant.

$i$ Rental units whose rents are not subject to rent regulation laws.

TABLE 3: Selected Results of Multinomial Logistic Regression Model Predicting

the Race/Ethnicity of In-Movers to New York City Rental Units, 1978-1987, Odds

Ratios(a)

$\begin{array}{ccc}\text { Black } & \text { Puerto Rican } & \text { Other Hispanic } \\ \text { vs. White } & \text { vs. White } & \text { vs. White }\end{array}$

Period (vs. 1984-87)

Borough (vs. Manhattan)

$\begin{array}{llcc}\text { Bronx } & 5.44(* \star *) & 7.87(* \star *) & 1.41 \\ \text { Brooklyn } & 2.84(* \star *) & 1.77(* *) & .56(* \star *) \\ \text { Queens } & 1.50 & 1.35 & 1.24 \\ \text { Staten Island } & 1.51 & .38 & .12(* \star *)\end{array}$

Subarea racial/ethnic composition $(b, c)$

(vs. predominantly white)

\section{Mixed Hispanic}

Mixed black

Predominantly nonwhite

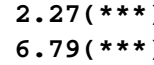

$6.79(* \star *)$

$20.20(* \star *)$
$2.78(* \star \star)$
$2.17(* \star \star)$
$9.28(* * *)$

$3.01(* * *)$

$2.43(* \star *)$

$9.73(* * *)$

Race/ethnicity of prior household

(vs. white)

\section{Black}

Puerto Rican

Other Hispanic
$40.27(* \star \star)$
$5.29(* \star *)$
$5.05(* * *)$
$6.24(* * *)$

$9.03(* \star *)$

$5.70(* \star *)$
$3.47(* \star *)$

$4.73(* * *)$

$10.33(* * *)$

Neighborhood quality(c)

Evaluation (vs. excellent/good)

Fair

$1.74(* * *)$

$1.92(* \star \star)$

$1.71(\star \star \star)$ 


\section{The constraints on minority housing choices, New York City 1978-1987.}

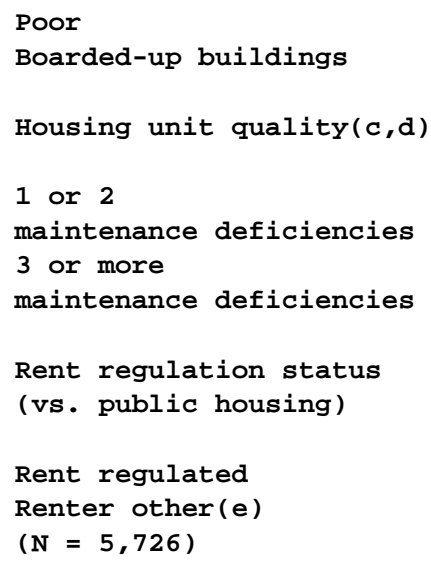

white/other.

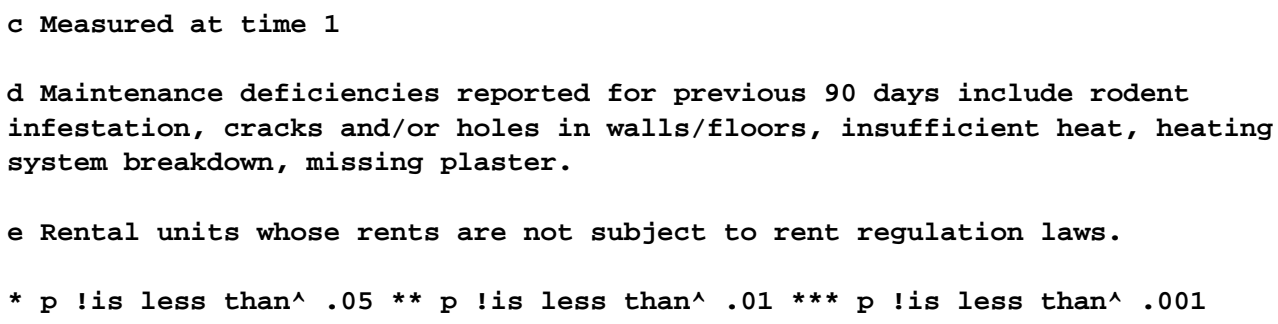

\section{ARE MINORITY HOUSING CHOICES LIMITED?}

In the preceding section, descriptive statistics made it clear that minority households acquire lower-quality housing than do white households, and that destinations differ markedly by race/ethnicity. However, because controls for economic status and preferences were absent, the preceding analysis left unanswered the question of whether housing consumption differences are due to such factors or to external constraints on minority housing choices arising from market segmentation. To better address this question, Table 3 presents selected results from the multinomial logit model that predicts the competing odds that a black, Puerto Rican, or other Hispanic household moves in relative to the odds that a white household moves in, in all rental units experiencing a change in occupancy.(7) The results are reported as odds ratios; an odds ratio greater than 1.00 indicates an enhanced likelihood of minority relative to white occupancy associated with that independent variable, while an odds ratio less than 1.00 indicates a reduced likelihood of minority relative to white occupancy.

When compared with the likelihood of white in-movement, many predictors of minority in-movement are similar in 


\section{The constraints on minority housing choices, New York City 1978-1987.}

direction, suggesting the influence of factors that generally isolate the residential locations of minority in-movers from those of white in-movers. In particular, the indicators of subarea racial/ethnic composition and prior household race/ethnicity unmistakably suggest divisions in the housing market along racial/ethnic lines. For instance, that location in minority (relative to predominantly white) subareas increases the likelihood that the in-moving household is black, Puerto Rican, or other Hispanic rather than white (rows 7 to 9) suggests the presence of barriers that essentially seal off white subareas from minority entry, while channeling minority in-movers into racially and ethnically mixed areas. Similarly, the odds of minority occupancy are significantly enhanced when the prior household is black or Hispanic rather than white (rows 10 to 12), indicating that white/minority contact in the housing market is extremely rare, even after controlling for differences in economic status.

Turning to the effect of borough location (rows 3 to 6), the results reinforce the notion that market divisions predetermine the destinations of racial/ethnic groups in ways that sustain aggregate patterns of racial/ethnic segregation. On the one hand, the effect of borough location is similar to that of subarea racial/ethnic composition and previous household's race/ethnicity in that it reveals divisions that generally serve to separate whites from minorities. On the other hand, the finding that different boroughs are associated with the in-movement of different minority groups suggests mechanisms that foster varying patterns of interminority proximity and distance. For instance, location in the Bronx and Brooklyn significantly increases the likelihood of black and Puerto Rican (relative to white) in-movement, suggesting one mechanism by which black/Puerto Rican proximity at the aggregate level may be achieved, and a second mechanism that separates whites from both blacks and Puerto Ricans. In contrast, location in Brooklyn and Staten Island depresses the likelihood of other Hispanic in-movement, indicating a process that may separate members of this group not only from whites but from blacks and Puerto Ricans as well. In short, the impact of borough location may reflect market processes that sort minority groups to different locations, isolating them in general from whites, but from each other as well.

Turning to neighborhood and housing unit characteristics, evidence supporting the hypothesis that black and Hispanic in-moving households are differentially limited to low-quality housing emerges in the significantly increased likelihood of minority (relative to white) in-movement associated with fair and poor (relative to good/excellent) neighborhood evaluation (rows 13 and 14). In addition, while the presence of one or two maintenance deficiencies does not differentiate between white and minority occupancies, the presence of three or more deficiencies increases the odds of black and Puerto Rican occupancy. While the descriptive analysis left open the possibility that economic status could explain racial/ethnic disparities in housing consumption, the independent effects of housing and particularly neighborhood quality uncovered here suggest that market segmentation may be at the root of racial/ethnic housing inequalities.

Location in neighborhoods with boarded-up buildings increases the odds of Puerto Rican in-movement relative to white in-movement (column 2, row 16), but does not significantly predict black or other Hispanic occupancy. That Puerto Rican occupancy is alone in being influenced by all three indicators of housing quality suggests that Puerto Ricans experience a distinct handicap (when compared to whites) in acquiring quality housing. This finding stands in contrast to the more typical finding that blacks encounter the stiffest barriers when seeking to relocate to higher-quality housing and neighborhoods, and underscores the advantages of analyzing minority housing choices within a multiethnic context. Since it is unlikely that Puerto Ricans would be singled out from other minority groups for discrimination, an alternative explanation may lie in the increased competition for housing that arises from Hispanic immigration to New York City. Because of overlapping ethnicities, growing Hispanic demand for housing may differentially impinge upon the housing options available to Puerto Ricans, with the result that the options remaining available to Puerto Ricans are located farther down on the continuum of quality. Similarly, other observers have posited that increasing competition from other Hispanics may lie at the heart of deteriorating Puerto Rican labor market outcomes (Tienda 1989). Thus, intergroup competition may harm the well-being of Puerto Ricans on a number of dimensions.

The chance of black and Puerto Rican (compared with white) occupancy is significantly lower in private- than in public-sector units, net of the influence of income and dependence on public assistance (last two rows). This finding may provide insight into the role that public housing plays in creating and maintaining the residential distributions of these groups. Others have suggested that public housing may contribute to aggregate levels of metropolitan racial segregation, although empirical research using tract-level data has not supported this view (Bickford \& Massey 1991). However, because many of the largest public housing projects in New York City constitute individual census tracts, the differential sorting of blacks and Puerto Ricans into public housing evidenced here would serve to pack individual tracts, increasing by definition the tract-level dissimilarity indices that are traditionally used in segregation research. Thus, while ecological analyses have been unable to detect a significant and direct role of public housing in maintaining metropolitan racial 


\section{The constraints on minority housing choices, New York City 1978-1987.}

segregation, it seems likely that the distinct flow of individual black and Puerto Rican households into public housing units uncovered in this study may contribute to aggregate spatial patterns.

\section{Discussion}

The goal of this study was to evaluate whether the housing choices of black and Hispanic households (relative to those of white households) were differentially restricted to low-quality traits and neighborhoods and to units vacated by other minorities. This study differs from earlier efforts by evaluating minority housing choices in a multigroup context rather than the more typical two-group context that implicitly assumes away the influence of interminority competition for housing. The results indicate that destinations differ markedly by race/ethnicity, net of the influence of household characteristics that determine housing demand. The results, then, provide evidence of social and market forces that operate not only to isolate whites from blacks and Hispanics, but to contribute to the disparities in housing quality that characterize New York's renter population.

Although the increased chance of black and Hispanic occupancy associated with unfavorable neighborhood evaluation suggests limited minority access to high-quality neighborhoods, the vagueness of this indicator prevents us from knowing precisely why these neighborhoods are poorly evaluated in the first place. The HVS asks residents to evaluate their neighborhood "as a place to live." Such subjective judgments may be influenced by any number of areal characteristics, including crime, local school quality, service provision, and racial composition (St. John \& Bates 1990; Stipak \& Hensler 1983). Thus, it is unclear if minority households are relegated to neighborhoods with inadequate infrastructures, or to neighborhoods where, perhaps, change in the ethnic mix has diminished white demand for housing (Massey \& Denton 1993). Without better indicators of neighborhood quality or qualitative data regarding residents' feelings about their neighborhoods, this interpretation remains purely speculative. However, the added influence of the more objective measures of housing unit maintenance and the presence of boarded-up buildings in the neighborhood in predicting black and Puerto Rican in-movement supports the notion that market segmentation impedes minority access to quality housing.

Borough location and particularly subarea racial/ethnic composition strongly and consistently influence the likelihood of minority occupancy. These findings may partially reflect the impact of unmeasured preferences for proximity to kin or social networks, or perhaps for neighborhood institutions, services, or businesses that are offered in a foreign language or that cater in some other way to the cultural needs of group members. It is also possible that preferences for different neighborhood racial/ethnic mixes cause whites, blacks, Puerto Ricans, and other Hispanics to move to different destinations. Previous research has documented a wide racial gap in such preferences, such that whites tend to prefer areas with few if any blacks, while blacks opt for areas with more of an equal share of both groups (Clark 1991; Farley 1993; Farley et al. 1978; Schuman, Steeh \& Bobo 1985). However, it seems more likely that these findings represent the persistence of barriers in the housing market that effectively predetermine which neighborhoods are accessible to different groups. Indeed, the findings that minority households are effectively barred from white subareas while whites apparently avoid ethnically diverse areas essentially mirror results of ecological analyses reported elsewhere (Denton \& Massey 1991). While it is impossible to identify the precise cause of such patterns with these data, because the most recent housing market audit ranked New York among the worst metropolitan areas in terms of the amount of bias directed at black and Hispanic home-seekers (Lueck 1991), it is extremely difficult to discount the contribution of institutionalized discrimination. Yet, these results are also consistent with Suttles's (1972) description of the city dweller's "cognitive map," which governs spatial movement by identifying neighborhoods having reputations that "defend" against entry by dissimilar others. Prior research has shown that blacks and whites share common knowledge about various neighborhoods, including the cost of housing but also the potential reaction to an in-moving household of differing race (Farley, Bianchi \& Colasanto 1979). Some have suggested that this general knowledge, by implicitly defining the appropriate places for whites and blacks to live, contributes to the maintenance of racially separate neighborhoods (Farley \& Allen 1987). Perhaps in New York City a similar force exists, sorting white, black, and Hispanic households into separate neighborhoods to avoid confrontation with other groups. Whatever the ultimate cause or causes, it seems likely that the marked racial/ethnic differences in destinations reported here contributed to the increase in racial/ethnic segregation during the 1980s cited at the start of this study.

By evaluating the predictors of black, Puerto Rican, and other Hispanic in-movement within a multigroup context, this study reveals mechanisms that may encourage spatial proximity between blacks and Puerto Ricans, but distance between these groups and other Hispanics. These mechanisms appear to operate on a spatial level, in that blacks and Puerto Ricans tend to move to different boroughs than do other Hispanics. Yet these mechanisms also appear to be 


\section{The constraints on minonity housing choices, New York City 1978-1987.}

rooted in the operation of market sectors, specifically the public and private sectors. The distinct flow of black and Puerto Rican households into public housing units, net of the influence of indicators of need for such housing, may help to explain why members of these groups tend to share the same census tracts while living separately from whites and other Hispanics. These findings shed a new light on the potential role of public housing in maintaining patterns of residential segregation. That is, while ecological analyses have been unable to decipher a significant and direct role of public housing in shaping residential patterns, the findings of this study suggest that the differential flow of black and Puerto Rican households into public housing units may pack individual tracts, thereby influencing tract-level measures of segregation.

In summary, this study demonstrates that white and minority movers experience different levels of access to housing of varying quality and in varying locations, net of differences in income and household composition. Since where one lives largely determines one's life chances, inequities in acquiring residence in high-quality locations may serve to perpetuate racial/ethnic disparities on various dimensions and across generations. Moreover, the finding that blacks and Hispanics are unlikely to move into white-vacated units, or into units located in predominantly white subareas, reflects the microlevel dynamic that sustains aggregate spatial patterns but also indicates that frequent and informal social contact across racial and ethnic boundaries is restricted beyond the limits placed by differences in economic status. In the absence of social interaction, group members cannot test the validity of stereotypes, which may preserve these beliefs and thus contribute to intergroup tensions (Farley \& Allen 1987; Turner \& Wienk 1993). These findings, therefore, demonstrate the continuing barriers to equal access within the urban housing market, and the constraints that prevent frequent, informal, and simple interactions between racial and ethnic groups.

Notes

1. I use the simple terms white and black throughout the remainder of this paper to refer to non-Hispanics of each race. By disaggregating only Puerto Ricans, I do not mean to imply that other Hispanic-origin groups are homogeneous; rather, the decision to group together non-Puerto Ricans was predicated by the need for adequate cell sizes. Asians are not included in this study since they are uniquely identified only in the last of the four waves of Housing and Vacancy Survey data used.

2. These indices of dissimilarity are based on the city, rather than the metropolitan area, and were computed from census summary tape files by Joe Salvo and Ron Ortiz of Fordham University.

3. Because rent regulation status may change upon vacancy, the value at time 2 is what potential in-movers evaluate. Upon vacancy (by out-movement or death of the householder with no coresiding family members to inherit the unit) rent-controlled units become un-regulated (if located in a building with five or fewer units) or enter the rent-stabilization system.

4. Doing so distinguishes the desired impact of racial/ethnic composition on in-movement from the potential impact of in-movement on racial/ethnic composition. Measuring subarea racial/ethnic composition at time 1 also means that it is unaffected by the definitional changes in race/ethnicity in the 1987 survey described above.

5. Retaining these cases limits the potential for bias since units lost to the sample are likely to be very different from those that were retained. The missing-data procedure allows cases with missing subarea information to contribute their valid values on other variables, but their influence on subarea composition (all are coded 0 ) is negated by controlling for their being missing (with the missing-data dummy).

6. Two alternate models were estimated to evaluate how the choice of this procedure for dealing with missing income data affects the analysis. In the first alternate model, cases with missing income were exclucled from the analysis, and in the second, they were assigned the group-time-specific mean. The results showed no substantive differences.

7. Because household characteristics are used mainly as statistical controls, they are neither shown nor discussed, but are available upon request from the author. Similarly, time period is used mainly as a control and is thus not discussed.

\section{References}

Alba, Richard. 1987. "Interpreting the Parameters of Log Linear Models." Sociological Methods and Research 16:45-77. 


\section{The constraints on minonity housing choices, New York City 1978-1987.}

Alba, Richard, and John Logan. 1993. "Assimilation and Stratification in the Homeownership Patterns of Racial and Ethnic Groups." International Migration Review 26:1314-40.

Aldrich, John, and Frank Nelson. 1984. Linear Probability, Logit, and Probit Models. Sage Publications.

Bean, Frank, and Marta Tienda. 1987. The Hispanic Population of the United States. Russell Sage Foundation.

Bianchi, Suzanne. 1981. Household Composition and Racial Inequality. Rutgers University Press.

Bianchi, Suzanne, Reynolds Farley, and Daphne Spain. 1982. "Racial Inequalities in Housing: An Examination of Recent Trends." Demography 19:37-51.

Bickford, Adam, and Douglas Massey. 1991. "Segregation in the Second Ghetto: Racial and Ethnic Segregation in American Public Housing, 1977." Social Forces 69:1011-36.

Buell, Emmet. 1982. School Desegregation and Defended Neighborhoods. Lexington Books.

Clark, W.A.V. 1991. "Residential Preferences and Neighborhood Racial Segregation: A Test of the Schelling Segregation Model." Demography 28:1-19.

Darden, Joe. 1987. "Choosing Neighbors and Neighborhoods: The Role of Race in Housing Preferences." Pp. 15-42 in Divided Neighborhoods: Changing Patterns of Racial Segregation, edited by Gary Tobin. Sage Publications.

Denowitz, Ronald. 1980. "Racial Succession in New York City, 1960-70." Social Forces 59:440-54.

Denton, Nancy, and Douglas Massey. 1988. "Residential Segregation of Blacks, Hispanics, and Asians by Socioeconomic Status and Generation." Social Science Quarterly 69:797-817.

----.. 1991. "Patterns of Neighborhood Transition in a Multi-Ethnic World: U.S. Metropolitan Areas 1970-1980." Demography 28:41-64.

DeSana, Judith. 1990. Protecting One's Turf: Social Strategies for Maintaining Urban Neighborhoods. University Press of America.

Duncan, Otis Dudley, and Beverly Duncan. 1957. The Negro Population of Chicago. University of Chicago Press.

Farley, Reynolds. 1993. "Neighborhood Preferences and Aspirations among Whites and Blacks." Pp. 161-91 in Housing Markets and Residential Mobility, edited by G. Thomas Kingsley and Margery Austin Turner. Urban Institute Press.

Farley, Reynolds, and Walter Allen. 1987. The Color Line and the Quality of Life in America. Russell Sage Foundation.

Farley, Reynolds, Suzanne Bianchi, and Diane Colasanto. 1979. "Barriers to the Racial Integration of Neighborhoods: The Detroit Case." Annals 441:97-113.

Farley, Reynolds, Howard Schuman, Suzanne Bianchi, Diane Colasanto, and Shirley Hatchett. 1978. "Chocolate City, Vanilla Suburbs: Will the Trend toward Racially Separate Communities Continue?" Social Science Research 7:319-44.

Fienberg, Stephen. 1989. The Analysis of Cross-Classified Categorical Data. MIT Press.

Galster, George. 1986. "More than Skin Deep: The Effect of Discrimination on the Extent and Pattern of Racial Residential Segregation in the United States." Pp. 119-38 in Housing Desegregation and Federal Policy, edited by John Goering. University of North Carolina Press.

Garfinkel, Irwin, and Sara McLanahan. 1986. Single Mothers and Their Children. Urban Institute Press. 


\section{The constraints on minority housing choices, New York City 1978-1987.}

Garza, Jose. 1983. "Hispanic Americans: Limited Housing Options." In A Sheltered Crisis: The State of Fair Housing in the Eighties, edited by U.S. Commission on Civil Rights. Civil Rights Commission.

Gurak, Douglas, and Mary Kritz. 1985. "Hispanic Immigration to the Northeast in the 1970s." Migration Today 18:6-12.

Hanushek, Eric, and John Jackson. 1977. Statistical Methods for Social Scientists. Academic Press.

Jackman, Mary, and Robert Jackman. 1980. "Racial Inequalities in Home Ownership." Social Forces 58:1221-34.

James, Franklin, and Eileen Tynan. 1986. "Segregation and Discrimination of Hispanic Americans: An Exploratory Analysis." Pp. 83-98 in Housing Desegregation and Federal Policy, edited by John Goering. University of North Carolina Press.

Knoke, David, and Peter Burke. 1980. Log-Linear Models. Sage Publications.

Krivo, Lauren. 1986. "Home Ownership Differences between Hispanics and Angles in the United States." Social Problems 33:318-33.

Lake, Robert. 1981. The New Suburbanites: Race and Housing. Center for Urban Policy Research.

Lee, Barrett, and Peter Wood. 1991. "Is the Residential Succession Model Place Specific? Patterns of Racial Change in Mixed Neighborhoods by Region and City, 1970-1980." Demography 28:21-40.

Long, Larry, and Daphne Spain. 1978. "Racial Succession in Individual Housing Units." Current Population Reports, Series P-23, no. 71. Government Printing Office.

Lueck, Thomas. 1991. "New York Ranks High in Housing Bias." New York Times, 3 Nov.

Mann, Evelyn, and Joseph Salvo. 1984. "Characteristics of New Hispanic Immigrants to New York City." Paper presented at the annual meeting of the Population Association of America, Minneapolis.

Marullo, Samuel. 1982. "Housing and Race: Black and White Differentials in Housing Consumption, Filtering, and Turnover." Ph.D. diss., Columbia University.

----. 1985. "Targets for Racial Invasion and Reinvasion: Housing Units Where Turnovers Occurred, 1974 and $1977 . "$ Social Forces 63:748-55.

Massey, Douglas, and Brooks Bitterman. 1985. "Explaining the Paradox of Puerto Rican Segregation." Social Forces 64:306-31.

Massey, Douglas, and Nancy Denton. 1985. "Spatial Assimilation as a Socioeconomic Outcome." American Sociological Review 50:94-106.

----. 1987. "Trends in the Residential Segregation of Blacks, Hispanics, and Asians, 1970-80." American Sociological Review 52:802-25.

-----. 1993. American Apartheid: Segregation and the Making of the Underclass. Harvard University Press.

Massey, Douglas, and Eric Fong. 1990. "Segregation and Neighborhood Quality: Blacks, Hispanics, and Asians in the San Francisco Metropolitan Area." Social Forces 69:15-32.

Massey, Douglas, and Adam Gross. 1991. "Spatial Assimilation Models: A Micro-Macro Comparison." Social Science Quarterly 72:347-60.

Massey, Douglas, and Brendan Mullan. 1984. "Processes of Hispanic and Black Spatial Assimilation." American Journal 


\section{The constraints on minority housing choices, New York City 1978-1987.}

of Sociology 89:836-73.

Newburger, Harriet. 1984. Recent Evidence on Discrimination in Housing. U.S. Department of Housing and Urban Development.

Pearce, Diana. 1979. "Gatekeepers and Homeseekers: Institutional Patterns in Racial Steering." Social Problems 3:325-42.

Quigley, John, and Daniel Weinberg. 1977. "Intra-Urban Residential Mobility: A Review and Synthesis." International Regional Science Review 2:41-66.

Rieder, Jonathan. 1985. Canarsie: The Jews and Italians of Brooklyn against Liberalism. Harvard University Press.

Rosenberg, Terry, and Robert Lake. 1976. "Towards a Revised Model of Residential Segregation and Succession: Puerto Ricans in New York, 1960-70." American Journal of Sociology 81:1142-50.

St. John, Craig, and Nancy Bates. 1990. "Racial Composition and Neighborhood Evaluation." Social Science Research 19:44-61.

SAS Institute. 1985. SAS User's Guide: Statistics. SAS Institute.

Schuman, Howard, Charlotte Steeh, and Lawrence Bobo. 1985. Racial Attitudes in America. Harvard University Press.

Stipak, Brian, and Carl Hensler. 1983. "Effect of Neighborhood Racial and Socioeconomic Composition on Urban Residents' Evaluations of Their Neighborhoods." Social Indicators Research 12:311-20.

Susser, Ida. 1982. Norman Street: Poverty and Politics in an Urban Neighborhood. Oxford University Press.

Suttles, Gerald. 1972. The Social Construction of Communities. Aldine.

Taeuber, Karl, and Alma Taeuber. 1965. Negroes in Cities. Aldine.

Tienda, Marta. 1989. "Puerto Ricans and the Underclass Debate." Annals 501:105-19.

Turner, Margery Austin, and Ronald Wienk. 1993. "The Persistence of Segregation in Urban Areas: Contributing Causes." Pp. 193-216 in Housing Markets and Residential Mobility, edited by G. Thomas Kingsley and Margery Austin Turner. The Urban Institute Press.

U.S. Bureau of the Census. 1979. 1978 New York City Housing and Vacancy Survey !MRDF^. U.S. Bureau of the Census !producer and distributor^.

----. 1982. 1981 New York City Housing and Vacancy Survey !MRDF^. U.S. Bureau of the Census !producer and distributor^.

----. 1985. 1984 New York City Housing and Vacancy Survey !MRDF^. U.S. Bureau of the Census !producer and distributor^.

----. 1988. 1987 New York City Housing and Vacancy Survey !MRDF^. U.S. Bureau of the Census !producer and distributor^.

U.S. Department of Housing and Urban Development. 1991. Report to Congress on Rent Control. U.S. Department of Housing and Urban Development.

Villemez, Wayne. 1980. "Race, Class, and Neighborhood: Differences in the Residential Return on Individual Resources." Social Forces 59:414-30. 


\section{The constraints on minority housing choices, New York City 1978-1987.}

Wienk, Ronald, Clifford Reid, John Simonson, and Frederick Eggers. 1979. Measuring Racial Discrimination in American Housing Markets: The Housing Market Practices Survey. U.S. Department of Housing and Urban Development.

Wilson, Franklin D. 1979. Residential Consumption, Economic Opportunity, and Race. Academic Press.

Yinger, John. 1991. Housing Discrimination Study: Incidence of Discrimination and Variations in Discriminatory Behavior. U.S. Department of Housing and Urban Development. 